\title{
Study on Revenue Distribution of Passenger Platform under the Integrated Transportation Value Chain
}

\author{
Yun Xiao ${ }^{a}$, Lang $\mathrm{Wei}^{\mathrm{b}}$ \\ School of Automobile, Chang'an University, Xian 710064,China

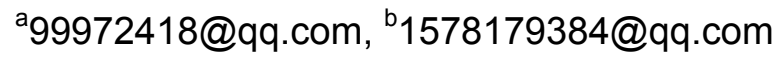

\begin{abstract}
Keywords: Transport economics; Integrated transportation Value Chain; Revenue distribution; Passenger platform; Completed transportation product
\end{abstract}

\begin{abstract}
As a new intermediary organization mode, passenger Platform play an important role in constructing integrated transportation value chain and providing completed transportation products. Revenue distribution of is an important prerequisite for the stability of the passenger platform. According to the characteristics of the passenger platform and to enhance the quality of transport services as the main line, the paper put forward the two stage multi-factor income distribution model, the cost compensation stage mainly consider the quality of service and cost of members, the product share stage is mainly considered resources, reputation and complaints of members, The analysis of example illustrates the model is scientific and innovative.
\end{abstract}

\section{Introduction}

The essence of the integrated transport is to provide a complete transportation products. In terms of supply or demand point of view, the transportation should be integrated transport chain[1]. However, the transport services are mostly provided by the sub-space distance, sub-transportation in China. The passengers have to find ways to link up the various transport by themselves, which increase the cost of passenger travel undoubtedly.

Passenger platforms are emerging intermediate organization. It relies on the virtual or physical intermediate organization, and attracts the operators engaging the basic transport service and passengers to join in. The distribution of income is an important prerequisite for the platform can create economic rents. how to design a rational income distribution scheme is the key issues for forming a stable contractual relation between the different transport companies, optimizing the transportation resources to provide complete products.

The research on the income distribution for the passenger platform currently is still in infancy. Literature [2-5] mainly studied corporate revenue distribution with the game theory, the network analysis and the NASH negotiation models. But firstly, it does not analyze deeply the income distribution pattern of the transport enterprises from the market characteristics of passenger transport, secondly, this modeling approach using static indicators and subjective qualitative analysis, and single measure the company's revenue, mandate, risk, and core competitiveness, not to study the overall value chain from the perspective of the transport system.

Based on the existing literature, we use a two-stage multi-factor distribution mode, build the income distribution model of the member enterprises on the passenger platform. It has certain significance for China in this period to accelerate the construction of comprehensive transportation system.

\section{Concept}

\subsection{Integrated transport value chain}

Integrated transport value chain refers that passenger business between different modes of transport, relies on the transport network with contract, to provide a complete transportation products for passengers. The Core is to create value and share value through mutual cooperation between the organization and enterprise with the different modes of transport, geographical space, and different 
property rights system. It is the pursuit of the best comprehensive benefits, The integrated transport value chain is a closed value chain and a complete passenger transportation process. A company may be able to establish a closed value chain alone. But at this stage, due to the institutional fragmentation factor or the asset-specific factor, the integrated transport value chain is completed by a number of companies .

\subsection{Constitution of the integrated transport value chain}

Integrated transport value chain consists of a set of basic transport operations. It is assumed that the passenger $\mathrm{F}$ in A city want to go to $\mathrm{C}$ city through $\mathrm{B}$ city.

W1: Local traffic patterns from the starting point to A city station (k choices);

W2: The main transport routes from A city station to B city station( $m$ choices);

W3: The main transport routes from B city station to $\mathrm{C}$ city station(n choices);

W4: Local traffic patterns from $\mathrm{C}$ city station to the ending point( $\mathrm{p}$ choices);

Then there are $\mathrm{n}\left(\mathrm{n}={ }_{k}^{1} C_{m}^{1} C_{n}^{1} C_{p}^{1}\right)$ transport sequences to the $\mathrm{F}$ traveler from A city station to $\mathrm{C}$ city station, and constituting the collection $\mathrm{x}\left(X \in X_{i}\right),{ }^{i}=1,2,3, \cdots \cdots, \mathrm{n}$.

The W1, W2, W3, W4 are completed by different transport companies in the current structure of the transport market.

\subsection{Passenger platform under the integrated transport Value Chain}

The passenger platform under integrated transport Value Chain consists of two basic parts. One is the enterprise $E_{p}$.it may be the virtual platform in the network, electronic information technology formed the basis, and can be a physical space, such as passenger field.Due to the obvious advantages in the network, openness and inclusiveness, the virtual platform is the focus of this study. Another is the enterprise engaging the basic transport operations, including long-distance transport, the city transportation and other services layer.

It is the main task of passenger transport platform to choose several transport sequence, constitute feasible collection y ( ${ }^{y \subseteq x}$ ) according to passenger demand. So passengers only need to face the platform $E_{p}$ to complete the entire transport process. The main market include the service platform $E_{p}$ and the transport companies bearing the business from the each basic transport, such as: W1, W2, W3 or W4.

Passenger platform under theIntegrated Transportation Value Chain not only changed the travel habits of passengers, but also change the traditional transport organization, and has distinctive characteristics.

\section{Revenue allocation analysis of Passenger platform}

\subsection{Analysis of Elements of revenue distribution}

Rational income distribution is a necessary condition for sustainable development of the passenger platform, the main factors to be consideredto distribute the platform income as follows:

(1) The number of basic transport services. Basic transportation services is the basis of integrated transport value chain and the revenue source of passenger transport platform. the income distribution of the passenger platform should take full account of the number of members of the transport task.

(2) Service quality. Service quality is a real-time dynamic index; each transport task can be evaluated by the quality of service, passenger transport service quality runs through the whole process of passenger travel, The service quality of member enterprises is directly related to the quality of the comprehensive transportation service, which has an important influence on the total income, so the income distribution of the passenger transportation platform should take full account of the service quality of the member enterprises.

(3) Corporate credit rating. Enterprise credit rating in a cycle is a static indicator; the credibility of the enterprise is a comprehensive evaluation of the members of the enterprise, including the members 
of the business management, business intelligence, development potential, performance ability and financial situation and other indicators. the enterprise should be inclined to high credit rating in the distribution of income.

(4) Transport resources. Transportation resources include the initial investment and maintenance costs, because each enterprise has different resources, the relative importance of the input of resources, so that the contribution of enterprises to the platform there are differences.

(5) Passenger complaints rate. Complaints include the individual demands, such as passenger protests, claims, but also the government and the media to solve the problem of behavior. The income distribution of enterprises and the rate of passenger complaints are negative, the lower the rate of complaints, the greater the income.

\section{2revenue distribution mode of passenger transport platform}

Revenue distribution mode mainly has the following two. One is the fixed payment mode according to the predetermined agreement, each member enterprises on the basis of the transport tasks, access to fixed payment from the total profit; another is the output sharing model: refers to all members of the enterprise in accordance with the coefficient of the total revenue of cooperation. member enterprises share the residual income, this model takes into account the members' effort level and risk of actual factors, reflects the interests of members and risk sharing principle.

According to the characteristics of passenger platform, the core enterprise $E_{p}$ acts as a unified settlement of the income distribution and role in the comprehensive transportation value chain, passenger platform will generate residual income in the bilateral market, all of the remaining income should not by $E_{p}$ exclusive occupy, but also reflects the different roles of member enterprises. so we must consider the advantages of these two models, divide into two stages in the process of distribution, and take the fixed payment model in the cost compensation phase, and take the output sharing model. Member enterprise incomes from the fixed payment of income and production share of two parts constitute.

Use $V_{t}^{k}$ to express the total benefits of any member enterprise $\mathrm{K}$, then

$V_{t}^{k}=V_{f}^{k}+V_{o}^{k}(1)$

$V_{f}^{k}$ :the revenue from fixed payment mode to enterprise $\mathrm{k}$.

$V_{o}^{k}:$ the revenue from output sharing model to enterprise $\mathrm{k}$.

\section{REVENUE Distribution Model}

\subsection{Basic ideas of the two stage multi-factor income distribution model}

Quality of service is throughout in the entire process of transportation. Before transportation services, platform treats enterprise grade credit assessment (assessment within a week)and other static indicators as determinants, and other real-time dynamic factor as determinants in evaluating transport tasks (evaluate of each task once). Thus, the revenue distribution is multiple-factor and two-stage model. Firstly, decompose each transport task in platform into several transport subtasks, and then measure cost of each transport subtask, set the average cost to benchmark revenue, actual revenue of member companies is a function related to subtasks completed quality information in the foundation of benchmark revenue. Then through the shared output mode, the main factor is corporate reputation's assessment, considering the investment, complaints and other indicators, calculate the final value of the income distribution.

$W_{i}$ stands for a complete transportation task, then $W_{i}=\{U T, T T ; T, D, S ; C Q, D S ; p i\}$

UT、TT are essential information, UT is the information of members enterprise which undertakes the basic transport service, TT is the information of transport task type; T、D、S is transport demand information, $\mathrm{T}$ is time requirements, $\mathrm{D}$ is service quality requirements, $\mathrm{S}$ is special needs during transport process( Parcel Service); CQ DS is feedback information, CQ is complete quality 
information, DS is complaint Information; $\mathrm{Pi}$ is return information which represents benchmark after member companies complete the subtasks.

According to the transport task expression, $p_{i}$ express the profit of transportation $\operatorname{task}^{W_{i}} \cdot{ }^{q_{i}}$ express the transportation task quantity of platform complete, ${ }^{{ }_{t}}$ express the total profit of passenger platform, the value is:

$V_{t}=\sum_{i=1}^{n} p_{i} q_{i}$

\subsection{Fixed revenue payment calculated based on the quality of service}

Passenger transportation service quality is the key factor to achieve great development of the service industry.

Let each sub-task benchmark $p_{i j}, q_{i j}^{k}$ expresses the completed quantity of each member company $\mathrm{k}$.cq can be divided into five levels $\mathrm{E} 、 \mathrm{G} 、 \mathrm{M} 、 \mathrm{P} 、 \mathrm{~F}$, Each level is set a value, respectively is $T_{\mathrm{E}}$ 、 $T_{G} 、 T_{M} 、 T_{P} 、 T_{F}$,correspond to the quality of service "excellent", "good", "medium", "pass" and "second" five levels. Thus revenue results of member companies shown in Table 1:

Table 1.Completed quality grading and revenue of transport sub-task.

\begin{tabular}{lllll}
\hline Quality & Assignment & Benchmark yield & Actual income & Quantity \\
\hline $\mathrm{E}$ & $T_{\mathrm{E}}$ & $p_{i j}$ & $T_{E} p_{\mathrm{ij}}$ & $n_{i j}^{k}(E)$ \\
\hline $\mathrm{G}$ & $T_{\mathrm{G}}$ & $p_{i j}$ & $T_{G} p_{\mathrm{ij}}$ & $n_{i j}^{k}(G)$ \\
\hline $\mathrm{M}$ & $T_{M}$ & $p_{i j}$ & $T_{M} p_{\mathrm{ij}}$ & $n_{i j}^{k}(M)$ \\
\hline $\mathrm{P}$ & $T_{P}$ & $p_{i j}$ & $T_{P} p_{\mathrm{ij}}$ & $n_{i j}^{k}(P)$ \\
\hline $\mathrm{F}$ & $T_{F}$ & $p_{i j}$ & $T_{F} p_{\mathrm{ij}}$ & $n_{i j}^{k}(F)$ \\
\hline
\end{tabular}

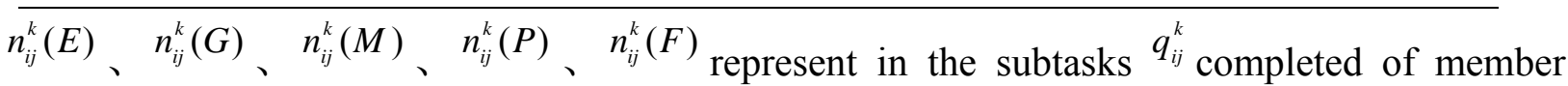
companies $\mathrm{k}$, the number of complete quality grade E, G, M, P and F, thus $q^{k}{ }^{k}$ is:

$q_{i j}^{k}=n_{i j}^{k}(E)+n_{i j}^{k}(G)+n_{i j}^{k}(\mathrm{M})+n_{i j}^{k}(\mathrm{P})+n_{i j}^{k}(\mathrm{~F})$

$p_{i j}^{k}$ expresses total profits of member companies $\mathrm{k}$ complete ${ }^{q_{i j}^{k}}$ transportation subtasks $^{W_{i j}}$, the value is:

$p_{i j}^{k}=n_{i j}^{k}(\mathrm{E}) \mathrm{T}_{\mathrm{E}} p_{\mathrm{ij}}+n_{i j}^{k}(\mathrm{G}) \mathrm{T}_{\mathrm{G}} p_{\mathrm{ij}}+n_{i j}^{k}(\mathrm{M}) \mathrm{T}_{\mathrm{M}} p_{\mathrm{ij}}+n_{i j}^{k}(\mathrm{P}) \mathrm{T}_{\mathrm{P}} p_{\mathrm{ij}}+n_{i j}^{k}(\mathrm{~F}) \mathrm{T}_{\mathrm{F}} p_{\mathrm{ij}}$

$V_{f}^{k}$ expresses total profits which member companies $\mathrm{k}$ achieve through completing transportation subtasks, namely the profit member companies achieved in the fixed payment phase, the value is:

$V_{f}^{k}=\sum_{i=1}^{n} \sum_{j=1}^{m} p_{i j}{ }^{k}$

\subsection{Calculation on output revenue sharing}

Passenger platform can create economic rents, namely it has residual income. Assignment of output revenue sharing should consider corporate reputation, resources, complaint rates and other factors, distributable income is the remaining income after fixed payment. If there are $\mathrm{h}$ member companies in the platform, thus total profit of all member companies achieved through completed subtasks is:

$V_{f}=\sum_{k=1}^{h} V_{f}^{k}$

Total revenue $V_{t}$ minus $V_{f}$ equal to $V_{o}$ (outputs revenue sharing can be assigned)

the formula is: 
$V_{o}=V_{g}-V_{f}=\sum_{i=1}^{n} p_{i} q_{i}-\sum_{k=1}^{h} V_{f}^{k}$

\subsubsection{Revenue distribution based on corporate credit rating}

Efficiently playing of passenger platforms depends on platform controls the entire transport value chain effectively and effective collaboration between different transport enterprises. As an intermediate organization, corporate credit rating can help to improve organizational efficiency. In the platform's income allocation, the higher the credit rating of member companies is, the more secondary income distribution is. $\xi_{X}^{k}(v)$ represents member companies $\mathrm{k}$ income distribution value based on the credit rating. Corporate credit rating is divided into five grades E、G、M、P、F, respectively represents $1,2,3,4,5$ score points. Suppose corporate credit rating vectors $X=\left(x^{1} x^{2} \mathrm{~K} x^{k} \mathrm{~K} x^{h}\right)$,thus

$\xi_{X}^{k}(v)=\frac{X^{k}}{\sum_{k=1}^{n} X^{k}} V_{o}$

\subsection{2 revenue based on resources}

Passenger transport industry is the basic network industry, which requires the full support of information network and effective convergence of infrastructure network, thus can have effects on economies of scale and scope. Huge transport facilities under different geographical space is difficult to complete through a single enterprise, it is not economical too. It is necessary for members company to integrate internal resources into a unified transport resources, passenger platform can reduces production costs and transaction costs. Thus, the resources invested is an important factor balancing enterprises profit distribution.

$\xi_{I}^{k}(v)$ expresses member companies $\mathrm{k}$ income distribution value based on investment. Suppose investment vector $Y=\left(Y^{1} Y^{2} \mathrm{~K} Y^{k} \mathrm{~K} Y^{h}\right)$,Distributable income ${ }^{V_{o}}$, thus:

$\xi_{Y}^{k}(v)=\frac{Y^{k}}{\sum_{k=1}^{n} Y^{k}} V_{o}$

\subsubsection{Revenue distribution based on the complaint rates}

$Z^{\prime}$ expresses the complaint rates of member companies, no complaint rate $Z=1-Z^{\prime}$.Assuming no complaint rate vector for each enterprise is $Z=\left(Z^{1} Z^{2} \mathrm{~K} Z^{k} \mathrm{~K} Z^{n}\right)$, $\xi_{Z}^{k}(v)$ expresses member companies $\mathrm{k}$ revenue distribution value based on the complaint rates, thus:

$$
\xi_{Z}^{k}(v)=\frac{Z^{k}}{\sum_{k=1}^{n} Z^{k}} V_{o}
$$

\subsubsection{Integrated distribution revenue}

The calculation of platform output shared gains choose the comprehensive evaluation method to calculate the distribution value of enterprise income.

Suppose $U=\left\{u_{1}, u_{1}, \cdots, u_{n}\right\}$ means $\mathrm{n}$ companies are involved in revenue distribution, $p=\left\{p_{1}, p_{1}, \cdots, p_{n}\right\}$ is the collection of evaluation factors, each enterprise in $U$ will use every factor in $\mathrm{V}$ to measure, get the matrix shown in Table 2 : 
Table 2 Observation Matrix Using Comprehensive Evaluation Method

\begin{tabular}{lllll}
\hline & $u_{1}$ & $u_{2}$ & $\cdots$ & $u_{3}$ \\
\hline$P_{1}$ & $a_{11}$ & $a_{12}$ & $\cdots$ & $a_{1 n}$ \\
\hline$P_{2}$ & $a_{21}$ & $a_{22}$ & $\cdots$ & $a_{2 n}$ \\
\hline$P_{3}$ & $a_{31}$ & $a_{32}$ & $\cdots$ & $a_{3 n}$ \\
\hline
\end{tabular}

we use the variation coefficient method to calculate the weight, the basic principle is that if the value of an index can clearly distinguish among the evaluation object, indicating that the index to distinguish information is rich, and should be given more weight.

The formula is: $v_{i}=\frac{s_{i}}{\left|\overline{x_{i}}\right|}$ 。 $\overline{x_{i}}=\frac{1}{n} \sum_{j=1}^{n} a_{i j}$ is the average index of item $\mathrm{i}, \quad S_{i}^{2}=\frac{1}{n-1} \sum_{j=1}^{n}\left(a_{i j}-\overline{x_{i}}\right)^{2}$ is index variance of item $i$. To normalize ${ }^{v} i$ to obtain the index weights.

$$
w_{i}=\frac{v_{i}}{\sum_{i=1}^{m} v_{i}}
$$

The output share revenue of member companies in platform for K:

$$
V_{o}^{k}=\sum_{i=1}^{3} \omega_{i} \xi_{i}(13)
$$

\section{Case Study}

Platform Enterprise $E_{p}$ choose $E_{a} 、 E_{b} 、 E_{c}$ 和 $E_{l}$ three basic passenger transport enterprises to participate in, to provides comprehensive transportation services for passengers. ${ }^{p}$ is responsible for the whole process of passenger transport organization, $E_{a} 、 E_{b} 、 E_{c}$ is responsible for the city's traffic in A、B and C city, $E_{l}$ is responsible for main transport between cities for A、B、C.

Integrated transport services platform for the first phase of the injection is a total of 40 million yuan. $E_{p}$ invest 20 million yuan, and the remaining four is the 5 million yuan. Integrated transport service platform is the main business of the city of A, B, C passenger transport services.

W1:Passenger transport between city A and B;

W2:Passenger transport between city $A$ and $C$;

W3:Passenger transport between city $\mathrm{B}$ and $\mathrm{C}$.

The full passenger transport products Wi can be subdivided into Wil (accepted passenger transport demand), $\mathrm{W}_{\mathrm{i} 2}$ (transport in starting city ), $\mathrm{W}_{\mathrm{i} 3}$ (intercity trunk transport) and $\mathrm{W}_{\mathrm{i} 4}$ (transport in destination city).

Set up a year, there are 100000 times for W1, 150000 times for W2, 200000 times for W3. Total revenue of 15 million yuan a year for comprehensive transport services passenger platform.

Each transport sub task requires only one member of the enterprises to complete. Benchmark revenue $\left({ }^{P_{i j}}\right)$ of each sub task and the number of transport sub tasks $\left({ }^{q_{i j}}\right)$ undertaken by each member enterprise are shown in table 3.Sub task quality level has E、G、M、P、F five levels, each level set a numerical value are $T_{\mathrm{E}}, T_{\mathrm{G}}, T_{M}, T_{P}, T_{F}$, and respectively correspond with "excellent", "good", "medium", "pass" and "second" five levels and respectively 110\%,105\%,100\%,95\%,90\%. 
Table 3 The Number of Cases about the Transport Sub-tasks Undertaken by Each Member

\begin{tabular}{|c|c|c|c|c|c|c|c|c|c|c|c|c|}
\hline line & W1 & & & & W2 & & & & W3 & & & \\
\hline $\begin{array}{l}\text { Task } \\
\text { Break } \\
\text { down }\end{array}$ & $W_{11}$ & $W_{12}$ & $W_{13}$ & $W_{14}$ & $W_{21}$ & $W_{22}$ & $W_{23}$ & $W_{24}$ & $W_{31}$ & $W_{32}$ & $W_{33}$ & $W_{34}$ \\
\hline $\begin{array}{l}p_{i j} \\
\text { (yua } \\
\text { n) }\end{array}$ & 10 & 3 & 6 & 5 & 10 & 3 & 7 & 4 & 10 & 5 & 8 & 4 \\
\hline$q_{i j}$ & \multicolumn{4}{|c|}{100000} & \multicolumn{4}{|c|}{150000} & \multicolumn{3}{|c|}{200000} & \\
\hline
\end{tabular}

\subsection{Phase on compensation costs: Fixed payment revenue distribution}

Transport sub-tasks' complete quality of four member companies is listed in Table 4-7.

Table 4 Complete subtasks quantity of different levels for ${ }^{E_{p}}$ companies

\begin{tabular}{l|l|l|l|l|l}
\hline & $n_{i 1}^{p}(E)$ & $n_{i 1}^{p}(G)$ & $n_{i 1}^{p}(M)$ & $n_{i 1}^{p}(P)$ & $n_{i 1}^{p}(F)$ \\
\hline $\mathrm{W} 1$ & 50000 & 20000 & 10000 & 10000 & 10000 \\
\hline $\mathrm{W} 2$ & 60000 & 30000 & 30000 & 20000 & 10000 \\
\hline $\mathrm{W} 3$ & 110000 & 30000 & 20000 & 20000 & 20000 \\
\hline
\end{tabular}

Table 5 Complete subtasks quantity of different levels for $E_{a}$ companies

\begin{tabular}{l|l|l|l|l|l|l|l|l|l|l}
\hline & $n_{i 2}^{a}(E)$ & $n_{i 2}^{a}(G)$ & $n_{i 2}^{a}(M)$ & $n_{i 2}^{a}(P)$ & $n_{i 2}^{a}(F)$ & $n_{i 4}^{a}(E)$ & $n_{i 4}^{a}(G)$ & $n_{i 4}^{a}(M)$ & $n_{i 4}^{a}(P)$ & $n_{i 4}^{a}(F)$ \\
\hline $\mathrm{W} 1$ & 15000 & 10000 & 10000 & 5000 & 10000 & 10000 & 15000 & 10000 & 10000 & 5000 \\
\hline $\mathrm{W} 2$ & 20000 & 20000 & 10000 & 15000 & 5000 & 20000 & 30000 & 10000 & 10000 & 10000 \\
\hline
\end{tabular}

Table 6 Complete subtasks quantity of different levels for $E_{b}$ companies

\begin{tabular}{l|l|l|l|l|l|l|l|l|l|l}
\hline & $n_{i 2}^{b}(E)$ & $n_{i 2}^{b}(G)$ & $n_{i 2}^{b}(M)$ & $n_{i 2}^{b}(P)$ & $n_{i 2}^{b}(F)$ & $n_{i 4}^{b}(E)$ & $n_{i 4}^{b}(G)$ & $n_{i 4}^{b}(M)$ & $n_{i 4}^{b}(P)$ & $n_{i 4}^{b}(F)$ \\
\hline $\mathrm{W} 1$ & 30000 & 10000 & 10000 & 5000 & 5000 & 15000 & 10000 & 5000 & 5000 & 5000 \\
\hline $\mathrm{W} 3$ & 60000 & 20000 & 20000 & 10000 & 10000 & 40000 & 20000 & 10000 & 5000 & 5000 \\
\hline
\end{tabular}

Table 7 Complete subtasks quantity of different levels for $E_{c}$ companies

\begin{tabular}{l|l|l|l|l|l|l|l|l|l|l}
\hline & $n_{i 2}^{c}(E)$ & $n_{i 2}^{c}(G)$ & $n_{i 2}^{c}(M)$ & $n_{i 2}^{c}(P)$ & $n_{i 2}^{c}(F)$ & $n_{i 4}^{c}(E)$ & $n_{i 4}^{c}(G)$ & $n_{i 4}^{c}(M)$ & $n_{i 4}^{c}(P)$ & $n_{i 4}^{c}(F)$ \\
\hline W2 & 20000 & 20000 & 20000 & 5000 & 5000 & 30000 & 20000 & 10000 & 10000 & 10000 \\
\hline W3 & 10000 & 10000 & 20000 & 10000 & 55000 & 5000 & 10000 & 20000 & 10000 & 50000 \\
\hline
\end{tabular}

Table 8 Complete subtasks quantity of different levels for ${ }^{E_{l}}$ companies

\begin{tabular}{l|l|l|l|l|l}
\hline & $n_{i 3}^{l}(E)$ & $n_{i 3}^{l}(G)$ & $n_{i 3}^{l}(M)$ & $n_{i 3}^{l}(P)$ & $n_{i 3}^{l}(F)$ \\
\hline $\mathrm{W} 1$ & 40000 & 30000 & 10000 & 10000 & 10000 \\
\hline $\mathrm{W} 2$ & 70000 & 40000 & 20000 & 10000 & 10000 \\
\hline $\mathrm{W} 3$ & 110000 & 40000 & 20000 & 20000 & 10000 \\
\hline
\end{tabular}


According to the formula (4-6), the fixed income payment of $E_{a} 、 E_{b} 、 E_{c}$ and $E_{l}$ under the quality-guided is: $V_{f}^{p}=4695000$ yuan, $V_{f}^{a}=765750$ yuan, $V_{f=1568750 y u a n, ~}^{b} V_{f=1383000 y u a n}^{c}$, $V_{f}^{l}=3134500$ yuan.

Excluding transportation task service quality, the fixed income payment of each member company is: $V_{f}^{\prime p}=4500000$ yuan , $V_{f}^{\prime a}=750000$ yuan , $V_{f}^{\prime b}=1500000$ yuan , $V_{f}^{\prime c}=1400000$ yuan , $V_{f}^{\prime \prime}=3250000$ yuan. The income difference between them is $\delta_{f}=V_{f}-V_{f}^{\prime}$.Thus $\delta_{f}^{p}=195000$ yuan,

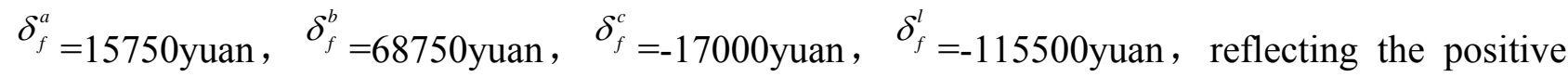
correlation between benefits and the quality of service.

\subsection{Profit distribution stage - redistribution of output share income}

According to the formula (7-8), calculate the total fixed income payment of all member companies

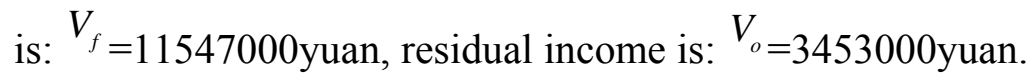

(1) Revenue based on corporate reputation

According to corporate credit rating $X=(5,4,3,1,2)$ and the formula (9) ,calculate the revenues based on cargo damage of all member companies: $\xi_{X}^{p}(v)=1151000$ yuan, $\xi_{X}^{a}(v)=920800$ yuan, $\xi_{x}^{b}(v)=690600$ yuan, $\xi_{x}^{c}(v)=230200$ yuan, $\xi_{X}^{l}(v)=460400$ yuan.

(2) The calculation of revenue based on resources

Vector Resources $\mathrm{Y}=(2000,500,500,500,500)$,according to the formula (10) ,calculate the revenues based on resources of all member companies: $\xi_{\mathrm{Y}}^{p}(v)=1726500$ yuan , $\xi_{\mathrm{Y}}^{a}(v)=431625$ yuan, $\xi_{\mathrm{Y}}^{b}(v)=431625 \mathrm{yuan}, \quad \xi_{\mathrm{Y}}^{c}(v)=431625 \mathrm{yuan}, \quad \xi_{\mathrm{Y}}^{l}(v)=431625 \mathrm{yuan}$.

(3) Revenue calculated based on passenger complaints

No complaint rate vector $Z=(96,90,80,65,70)$, according to the formula (11) ,calculate the revenues based on complaints of all member companies: $\xi_{Z}^{p}(v)=826653$ yuan , $\xi_{z}^{a}(v)=602768$ yuan, $\xi_{z}^{b}(v)=688878$ yuan, $\xi_{z}^{c}(v)=559713$ yuan, $\xi_{z}^{l}(v)=774988$ yuan .

(4) The calculation of comprehensive income distribution of output sharing Matrix of observation and calculation results shown in Table 9:

Table 9 Complete transportation product Matrix of observation and calculation results

\begin{tabular}{l|l|l|l|l|l}
\hline & Ep & Ea & Eb & Ec & El \\
\hline Credibility & 5 & 4 & 3 & 1 & 2 \\
\hline Resources & 2000 & 500 & 500 & 500 & 500 \\
\hline Complaints & 96 & 70 & 80 & 65 & 90 \\
\hline
\end{tabular}

According to the formula (12):

Weight vector $w=\left[\begin{array}{lll}0.3449 & 0.5487 & 0.1064\end{array}\right]^{T}$

The fourth step is to calculate the output sharing comprehensive income $V_{o}^{k}$ 
According to the formula (12), calculate the output sharing comprehensive income of all member companies: $V_{o}^{p}=1432245$ yuan,$V_{o}^{a}=618544$ yuan, $V_{o}^{b}=548321$ yuan,$V_{o}^{c}=375793$ yuan , $V_{o}^{l}=478097$ yuan.

\subsection{The Final Benefits of All Member Companies}

The final income distribution of $E_{a} 、 E_{b} 、 E_{c}$ and $E_{l}$ is: $V_{t}^{p}=V_{f}^{p}+V_{o}^{p}=6127245 y u a n$, $V_{t}^{a}=V_{f}^{a}+V_{o}^{a}=1384294$ yuan,$V_{t}^{b}=V_{f}^{b}+V_{o}^{b}=2117070$ yuan, $V_{t}^{c}=V_{f}^{c}+V_{o}^{c}=1758793$ yuan, $V_{t}^{l}=V_{f}^{l}+V_{o}^{l}=3612597$ yuan.

\section{Conclusions}

Under the environment of transportation economy control policy and industry association structure, The passenger transport platform can reduce transaction costs, reduce moral hazard and speed up the formation of transportation network economy.

This paper mainly draws the following conclusions:

(1) The scientific interests distribution mechanism is the basis of the integrated transport platform. The number of services, quality of service, credit rating, transportation resources and passenger complaints must be considered as they are important factors to adjust the distribution of income.

(2) The income distribution is divided into two stages, the cost compensation and the output sharing. The basic income of the member enterprises is guaranteed by the cost compensation. The output sharing stage reflects the cooperation principle of the benefit sharing.It conforms to the market characteristics that small and medium transportation enterprise's ability to resist risk is weak and the safeguard transportation cost is high,which is easy to be accepted by the member enterprise.

(3) In the cost compensation stage, it takes transportation sub task of the member enterprises as benchmark revenue $\left({ }^{P_{i j}}\right)$, and it evaluates service quality $\left({ }^{T_{i j}}\right)$ of each transport sub task $\left(q_{i j}\right)$ that member companies undertake. The initial income of member enterprises is a function which is positively related to the benchmark revenue $\left({ }^{P_{i j}}\right), \operatorname{transportation} \operatorname{task}\left({ }^{q_{i j}}\right)$ and service quality $\left({ }^{T_{i j}}\right)$, which reflects the positive correlation of transportation service quality ;In the output stage, the variation coefficient method is used to determine the index weight, and to distribute the surplus income of the passenger transportation platform, which reflects the difference of the contribution of the members, the simplicity of the calculation method, the strong practical significance of the income distribution model.

(4) The result shows that $E_{p}$ dues to the core market position in the integrated transport value chain, as well as higher corporate credit rating and the quality of services, access to the distribution of income excess; Although $E_{l} 、 E_{b}$ is in the secondary position in the integrated transport value chain, it completes more transport tasks, higher corporate credit rating and higher quality of service, which obtain higher revenue; $E_{a} 、 E_{c}$ is in low corporate credit rating and low quality of service, which reduce its income distribution.

\section{References}

[1]RONG Chao-he. Direction of Reorganizing Railway: A Perspective from the Specialty of Integrated Transport Products[J]. Journal of Northern Jiaotong University(Social Sciences Edition), 2002,1(1):13-18.

[2]WU Lang. The Method of Prof it Al location of Dynamic Logistic Alliance under the Mode of Product Share Contract[J].Systems Engineering. 2009,(05):29-33. 
[3]WANG Zhen-feng, WANG Xu, DENG Lei. Study on Service Supply chain System Benefit Distribution Based on Shapley Value Modification. Computer Engineering and Applications, 2011, 47 (26) : 235-237.

[4]LIU Lang, TANG Hai-jun, CHEN Zhong-jun. Application of the Shapley Value in Game Analysis of Benefit Distribution of Agile Virtual Enterprise[J]. Industrial Engineering Journal. 2006,9（6）: 118-120.

[5]MA Yue-ru, WANG Xiong. Partner Selection Model Based on Fuzzy Language Group Decision-Making Method for Dynamic Logistics Alliance under Multiple Time Periods[J]. Systems Engineering. 2008,26(6):32-36.

[6]LI Jin, LI Xiao-ming. Research on Modern Logistics Industry, Market Structure and Organization Mode Based on Perspective of Enterprise[J]. Journal of Highway and Transportation Research and Development, 2015,32(05):149-153.

[7]JIANG Jun. Risk Assessment of Construction Supply Chain Based on Multi-level Fuzzy Comprehensive Evaluation Method[J]. 2014,31(10)126-129.

[8] SUN Lu, ZHOU Zheng-bing, JIN Jiao-ping, et al. Assessment of Weather Condition for Traffic Safety of Mountain Highway Based on Fuzzy Entropy and Analytic Hierarchy Process[J].Journal of Highway and Transportation Research and Development, 2011, 28(12):138-144.

[9]POWELL W B,SHEFFI Y. The Convergence of Equilibrium Algorithms with Predetermined Step Sizes [J] .Transportation Science,1982, 16(1): 44-55.

[10]Das TK Teng(B-S). Instabilities of Strategic Alliances: An Internal Tensions Perspective[J]. Organization Science, 2000,(11): 77-101.

[11]ZHANG Feng-dan. Research on Quality Evaluation System of Road Passenger Transportation Service of China[D].Xi'an: Chang'anUniversity,2009. 